\title{
Bionanocompósitos e Novas Tendências em Engenharia de Biomassa
}

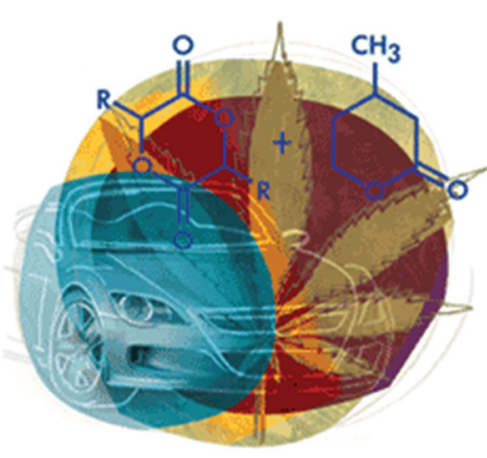

O Prof. Mohini Sain, diretor do Centro de Biocompósitos e Processamento de Biomateriais da Universidade de Toronto no Canadá esteve em visita ao Brasil de dezembro/2007 à fevereiro de 2008 através do Programa Professor Visitante da Fapesp e neste período ministrou um curso sobre bionanocompósitos na Universidade São Francisco, visitou empresas no estado de São Paulo, Rio de Janeiro e Rio Grande do Sul e proferiu algumas palestras. No dia 30 de janeiro o Prof. Mohini participou de um Workshop de Bionanocompósitos com Aplicação na Indústria Automobilística, organizado pela ABPol, nas dependências da ABIMAQ, e contou com mais de 50 pessoas. Durante a Mesa Redonda, que discutiu "Aplicações

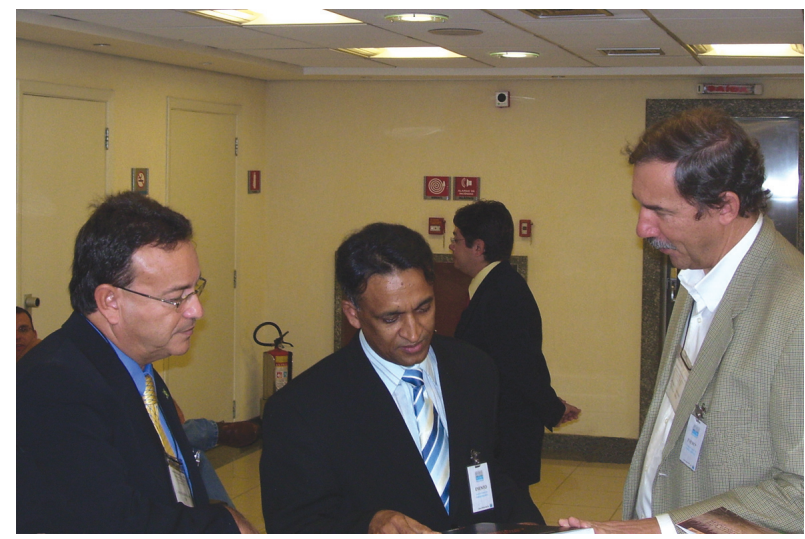

Prof. Carlos Alberto Correa, Prof. Mohini Sain e Prof. Sebastião Canevarolo.

de Biocompósitos", estavam presentes os Profs. Dr. Carlos Alberto Correa (USF-Itatiba/SP), Prof. Dr. Alcides L. Leão (UNESP-Botucatu/SP), Eng. Julio Harada (Basf S/A) e Dr. José Manoel Marconcini (Embrapa-São Carlos/SP).

Em Toronto, o Prof. Mohini é responsável por um laboratório com excelente infra-estrutura dedicado a estudos de fenômenos complexos relacionados a obtenção de bioprodutos de origem vegetal, isolamento, purificação e caracterização de biocelulose, isolamento e caracterização de microfibrilas a partir de raízes e fibras naturais, filmes de biocompósitos para aplicações em embalagens além do desenvolvimento de fibras naturais de alto desempenho para uso em compósitos celulósicos, processamento e avaliação de durabilidade de biocompósitos dentre outros aspectos correlatos.
Os principais tópicos abordados pelo Prof. Sain no Brasil referem-se à substituição da matriz energética hoje fortemente baseada em combustíveis fósseis por processos sustentáveis e materiais de fontes renováveis. Segundo Sain, a difusão do uso do automóvel como principal meio de transporte e símbolo de status nas sociedades modernas não está restrito apenas à queima de combustíveis fósseis e os gases do efeito estufa gerados pelos motores de combustão. Na verdade, estima-se que a energia necessária para a fabricação de um automóvel está em torno de um décimo da energia utilizada por este mesmo carro durante a sua vida útil. Analogamente, cerca de $10 \%$ do total de emissões de carbono produzidas durante a vida útil de um veículo de passageiros de porte médio é gerada durante a manufatura do veículo.

A tendência para o desenvolvimento de tecnologias que reduzam o consumo de combustíveis fósseis nos processos de manufatura começa a despertar grande interesse com os aumentos constantes do preço do petróleo. Este fator combinado com as preocupações ambientais com as emissões

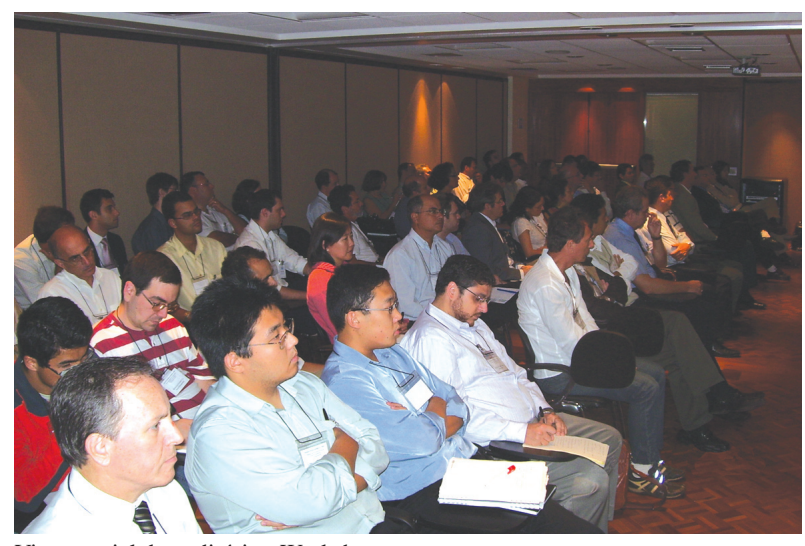

Vista parcial do auditório - Workshop

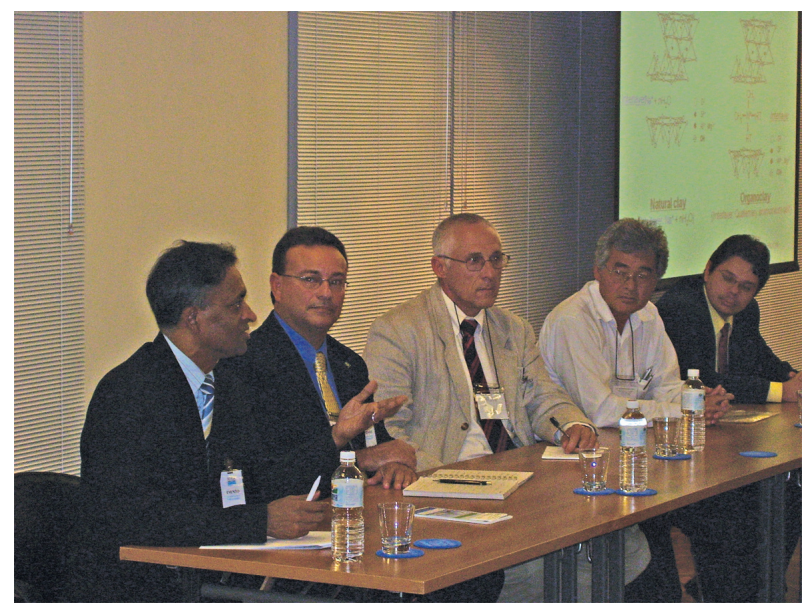

Mesa Redonda: Prof. Sain, Prof. Carlos Alberto, Prof. Alcides L. Leão, Eng. Julio Harada e Dr. José M. Marconcini. 


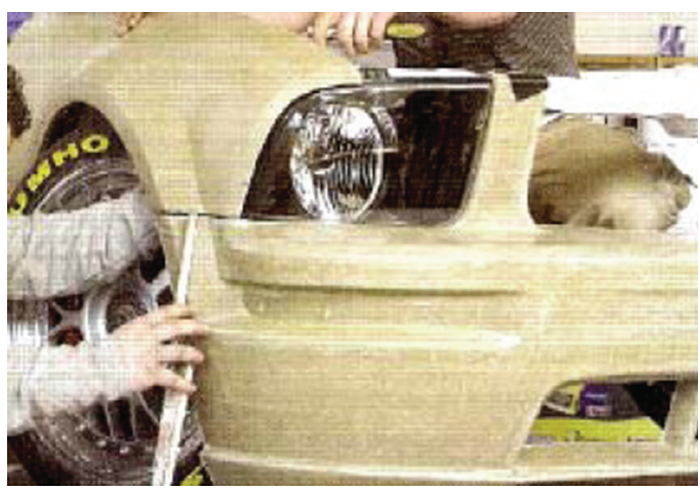

Ford Mustang GT Racing Car

Flax/Linseed oil - Structural Parts

de gases do efeito estufa e uma forte competição global no setor de produção desviou a atenção dos pesquisadores de recursos convencionais para recursos mais baratos, abundantes e renováveis tais como recursos florestais e de biomassa.

Na manufatura de componentes automobilísticos, os setores com maior perspectiva de crescimento são o de desenvolvimento de não-metais, plásticos e compósitos. Muitos componentes automotivos utilizados em interiores, incluindo partes estruturais são moldadas por injeção e são $100 \%$ recicláveis.

A proposta do Prof. Sain é transformar a indústria de fibras celulósicas em matérias-primas para biocompósitos através da extração de microfibrilas e nanofibrilas de biomassa para utilização em inúmeros setores - aeronáutico, componentes automotivos e dispositivos para aplicações médicas. Estes materiais totalmente inovadores podem apresentar uma rigidez de até $167 \mathrm{GPa}$ no caso de CNF (Nanonofibrilas de Celulose) ou até 300-600GPa no caso de CNW (Whiskers de celulose). O desenvolvimento de parachoques de automóveis com elevada relação rigidez/tenacidade a partir de materiais reforçados com CNF e CNW está entre os objetivos de Sain. O Prof. Sain é um dos poucos pesquisadores da Universidade de Toronto que vê na transferência de tecnologia o principal foco de seus subsídios acadêmicos e por conta disso o seu trabalho tem atraído grande interesse industrial. Além de receber subsídios industriais para financiamento de suas pesquisas, Sain detém inúmeras patentes bem como fundou a empresa "spin-off" Greencore a partir dos resultados de suas pesquisas.

No hemisfério norte (pra variar!) o desenvolvimento de biocompósitos de alto desempenho para aplicações em componentes automobilísticos está bem avançado! Recentemente um conglomerado de Universidades norte-america-
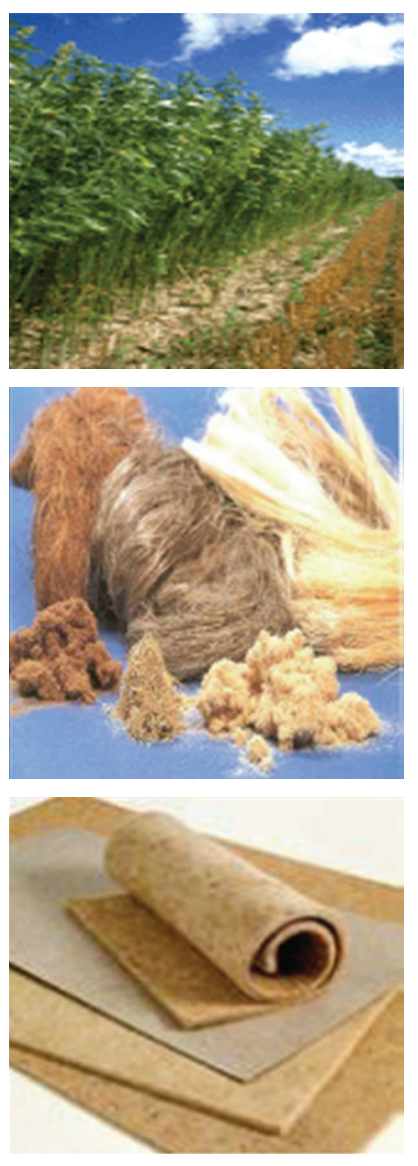

nas investiu no desenvolvimento de um "Agro-carro" - um veículo construído a partir de componentes biodegradáveis, e compósitos de fibras naturais. Durante o seu ciclo de vida, estes materiais renováveis, bioplásticos e resinas emitem muito menos gases do efeito estufa do que seus contratipos obtidos a partir do petróleo. Com o petróleo atingindo níveis de US\$ 100 o barril, estes componentes começam a tornar-se atrativos comercialmente para as empresas automotivas, uma vez que as matérias-primas das quais eles são obtidos - amidos, açúcares, óleos vegetais e fibras naturais - tem-se tornado cada vez mais competitivos com óleo cru.

O projeto Auto21 formado por um grupo de universidades canadenses também recebeu um fundo de $5 \mathrm{mi}-$

lhões de doláres para desenvolver um carro com essas características. O projeto prevê uma fusão entre biotecnologia e nanotecnologia, resultando em materiais alta tecnologia de origem celulósica.

Os desafios que estão sendo colocados hoje para viabilização do uso destas matérias- primas em escala industrial são investimentos em processos de extração de nanofibrilas e whiskers de celulose, e processos de transformação que tornem a engenharia dos bionanocompósitos competitiva com as tecnologias existentes. Empresas como Toyota já descobriram que o automóvel do fututo precisa não apenas reduzir a queima de combustíveis fósseis mas também reduzir drasticamente o consumo de energia empregado na transformação dos componentes automotivos. O Brasil desempenha um papel importante na liderança de produzir energia a partir de biomassa tais como os casos do álcool e do biodisel. O desafio agora é continuar investindo em pesquisas de novas tecnologias sustentáveis e que possibilitem a transformação da biomassa em materiais de alto desempenho.

\section{Matéria elaborado pelo Prof. Dr. Carlos Alberto Correa - Coordenador do Programa de Pós-Graduação em Engenharia e Ciência dos Materiais, Universidade São Francisco, Campus Itatiba, SP}

